
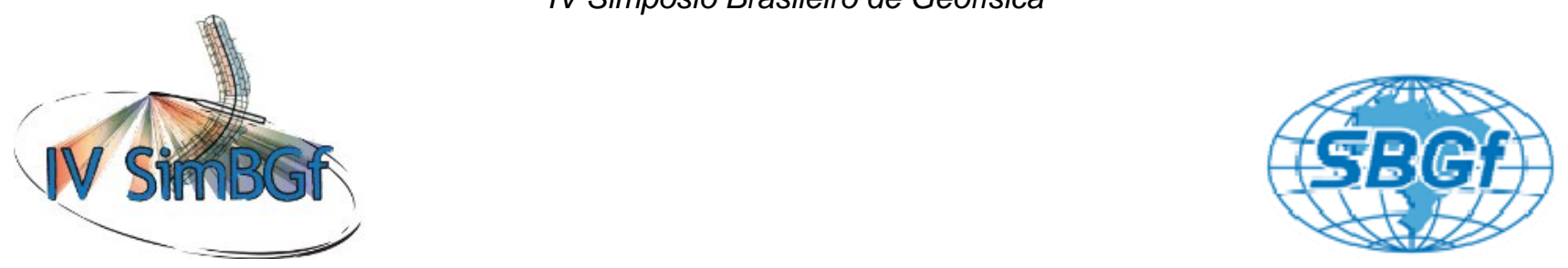

\title{
O Estudo da espessura crustal e razão Vp/Vs para as estações da Rede Sismográfica Nacional (RSN-SIS-UnB).
}

Diogo Farrapo Albuquerque, César Garcia Pavão, George Sand França \& Paulo Gustavo N. Silva, Instituto de Geociências, Observatório Sismológico (SIS), IG-UnB.

Copyright 2004, SBGf - Sociedade Brasileira de Geofísica

Este texto foi preparado para a apresentação no IV Simpósio de Geofísica da Sociedade Brasileira de Geofísica, Brasília,14-17 de novembro de 2010. Seu conteúdo foi revisado pela Comissão Tecno-científica do II SR-SBGf mas não necessariamente representa a opinião da SBGf ou de seus associados. E proibida a reprodução total ou parcial deste material para propósitos comerciais sem prévia autorização da SBGf.

\section{Resumo}

A Função do Receptor tem sido amplamente utilizada para a determinação de espessura crustal e razão $\mathrm{Vp} / \mathrm{Vs}$. Em 2006, o Observatório Sismológico da Universidade de Brasília iniciou a instalação da Rede Sismográfica Nacional, com o propósito de monitorar a atividade sísmica natural e desencadeada por reservatórios. Assim, foram usadas seis estações desta rede para para o cálculo das espessuras crustais e razões $V p / V s$. São ela: BRA7 (Brasília-DF), CAN3 (Cana Brava-GO), FOR1 (Fortaleza-CE), JAN7 (Itacarambi-MG), PDRB (Porto dos Gaúchos-MT) e TUCA (Tucuruí-PA). A Função do Receptor foi aplicada no domínio da freqüência (Langston, 1979; Owens, 1984; Ammon, 1991) e para as estimativas de espessura crustal e a razão Vp/Vs usamos o programa HK-Stacking (Zhu \& Kanamori, 2000). Os valores preliminares de espessura crustal variaram de 31,0 a $42,0 \mathrm{Km}$; a razão $\mathrm{Vp} / \mathrm{Vs}$ variou de 1,68 a 1,83. Essa variação está consistente com valores obtidos na literatura.

\section{Introdução}

A Função do Receptor (FR) é uma técnica geofísica que utiliza registros telessísmicos para estudar as diversas estruturas que compõem a subsuperfície. Basicamente, esta técnica é utilizada para estimar a espessura da crosta e a razão Vp/Vs logo abaixo de uma estação sismográfica.

Esse trabalho tem como objetivo estimar as espessuras crustais e razão $\mathrm{Vp} / \mathrm{Vs}$ sob as estações da Rede Sismográfica Nacional (RSN) do Observatório Sismológico e comparar com os valores obtidos por outros pesquisadores, além de aumentar o banco de dados referente aos valores de espessura crustal para o território brasileiro.

\section{Método}

A Função do Receptor utiliza o princípio básico de que a onda $\mathrm{P}$ ao atravessar uma descontinuidade, parte de sua energia é convertida em onda $S$ (Ps) e em diversas reverberações (reflexões múltiplas - PpPms). O ângulo de incidência das ondas sísmicas na interface CrostaManto é geralmente menor do que $40^{\circ}$ para sismos entre $30^{\circ}$ e $90^{\circ}$ de distância, o que significa que haverá um registro de onda $\mathrm{P}$ dominante na componente vertical do sismômetro e a onda Ps será dominante na componente radial.

A Função do Receptor é a deconvolução da componente radial pela vertical. Este processo isola a resposta do receptor e o resultado contém as assinaturas das fases convertidas e as reflexões múltiplas (Langston, 1979; Owens, 1984; Ammon, 1991).

\section{Processamento dos dados}

Foram selecionados telessismos com epicentros variando entre $30^{\circ}$ e $90^{\circ}$ de distância e magnitude a partir de 4,5 $m_{B}$. A inspeção visual dos eventos foi realizada com o programa SAC (Seismic Analysis Code, Goldstein \& Snoke, 2005) e a deconvolução no domínio da frequência foi feita pelo programa pwaveqn (Ammon, 1991). O empilhamento foi feito através do programa HK-Stacking (Zhu \& Kanamori, 2000).

\section{Análise dos Dados e Resultados}

Os valores obtidos de espessura crustal e razão Vp/Vs estão listados na Tabela 1.

Tabela 1 - Resultados obtidos de espessura crustal e razão $V p / V s$.

\begin{tabular}{|c|c|c|c|c|}
\hline Estação & $\begin{array}{c}\text { Prof. } \\
(\mathrm{Km})\end{array}$ & $\begin{array}{c}\mathbf{V p} \\
(\mathrm{Km} / \mathrm{s})\end{array}$ & $\mathbf{V p / V s}$ & $\begin{array}{c}\text { Correlação } \\
(\%)\end{array}$ \\
\hline BRA7 & $42,0 \pm 2,3$ & 6,4 & $1,70 \pm 0,05$ & $-97,6$ \\
\hline FOR1 & $32,8 \pm 0,9$ & 6,3 & $1,73 \pm 0,03$ & $-83,1$ \\
\hline JAN7 & $40,3 \pm 1,0$ & 6,4 & $1,70 \pm 0,02$ & $-91,2$ \\
\hline PDRB & $37,6 \pm 1,5$ & 6,4 & $1,68 \pm 0,05$ & $-7,2$ \\
\hline CAN3 & $31,1 \pm 2,5$ & 6,4 & $1,84 \pm 0,06$ & -99 \\
\hline TUCA & $30,6 \pm 4,5$ & 6,4 & $1,79 \pm 0,10$ & 67,5 \\
\hline
\end{tabular}

A Figura 1 mostra o resultado da Função do Receptor para a estação BRA7. É possível ver claramente a onda $P$ direta e a onda $P$ refratada na descontinuidade de Mohorovicic (onda Ps). As estimativas de espessura crustal e razão $\mathrm{Vp} / \mathrm{Vs}$ obtidas foram $42,0 \pm 2,3 \mathrm{Km}$ e 1,70 $\pm 0,05$, respectivamente (Figura 2 ).

A Figura 3 mostra o resultado da Função do Receptor para a estação CAN3. É possível ver claramente a onda $P$ direta e a onda $P$ refratada na descontinuidade de Mohorovicic (onda Ps). As estimativas de espessura crustal e razão $\mathrm{Vp} / \mathrm{Vs}$ obtidas foram $31,1 \pm 2,3 \mathrm{Km}$ e 1,84 $\pm 0,06$, respectivamente (Figura 4). 


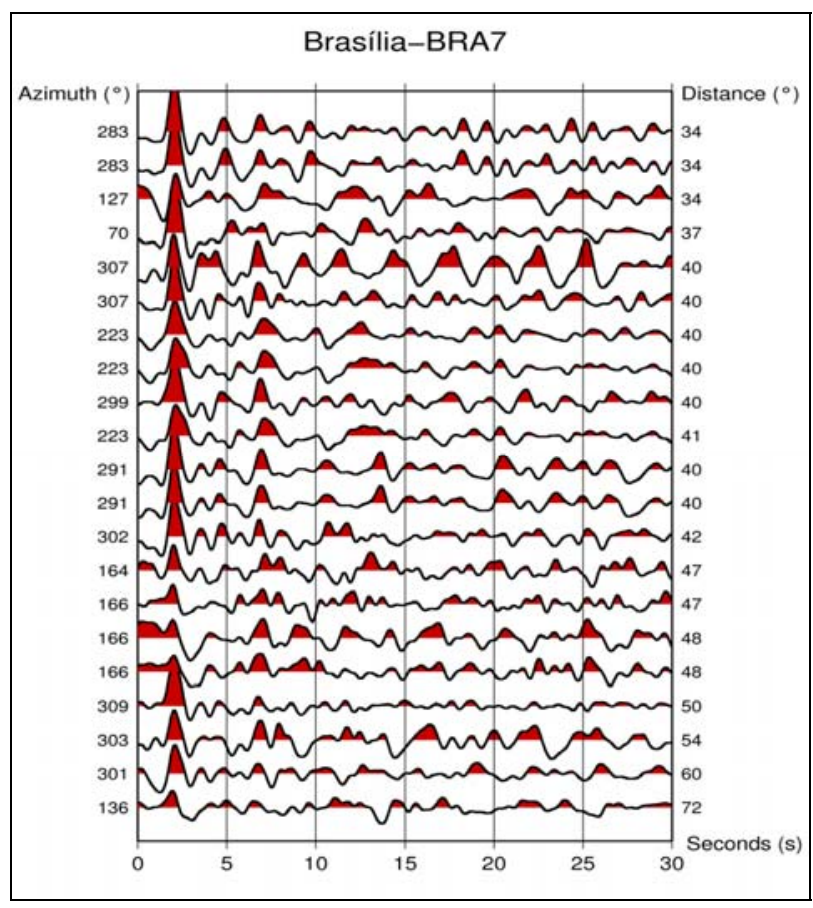

Figura 1 - Função do Receptor para vários azimutes e distâncias para estação BRA7.

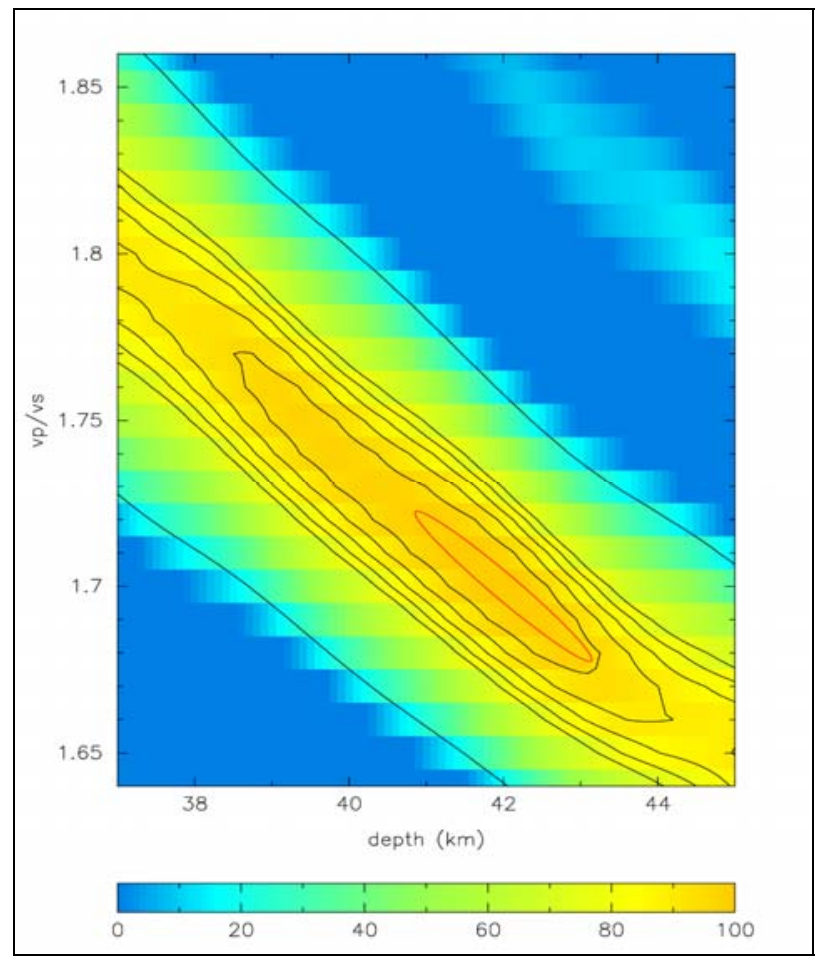

Figura 2 - Resultado do HK-Stacking para a estação BRA7.

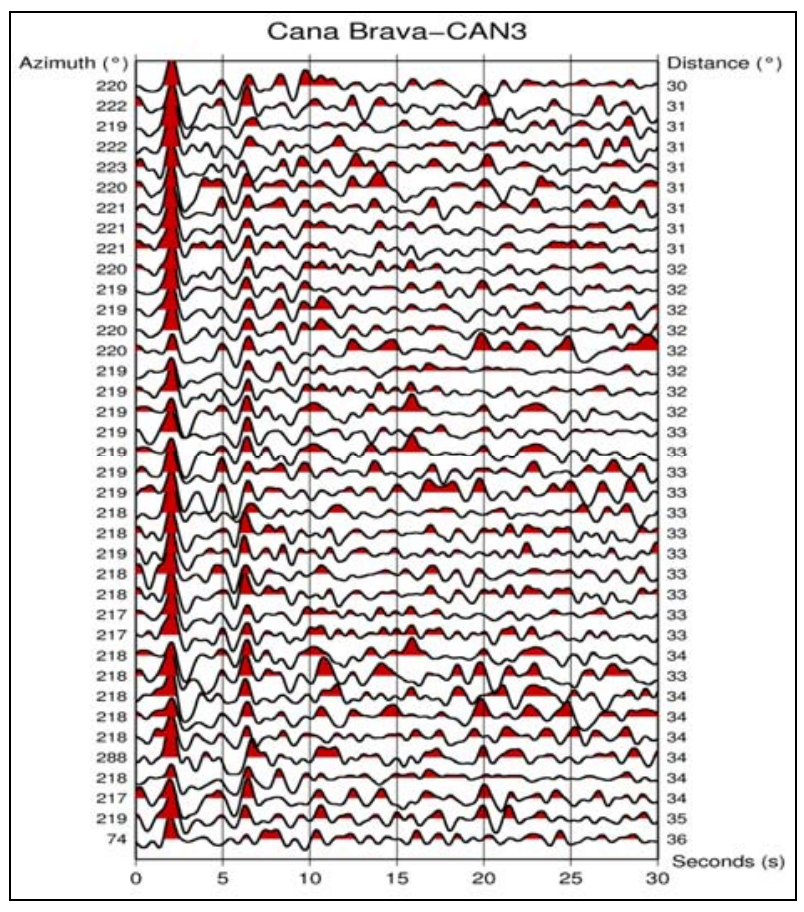

Figura 3 - Função do Receptor para vários azimutes e distâncias para estação CAN3.

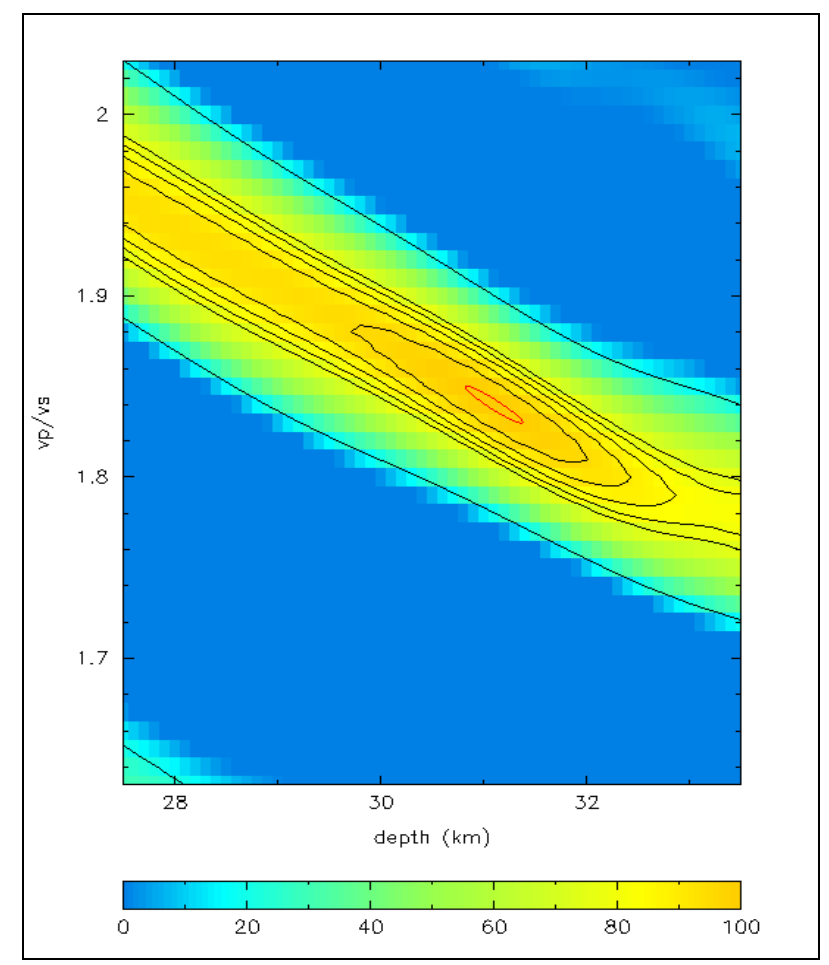

Figura 4 - Resultado do HK-Stacking para a estação CAN3. 


\section{Discussão e Conclusões}

Apesar de termos usado um valor médio para a velocidade da onda $P$ na crosta, os resultados preliminares são bastante satisfatórios. Esses valores são corroborados por estimativas feitas com estações sismográficas próximas àquelas utilizadas neste trabalho ou na mesma província geológica. Isso mostra a qualidade do trabalho, apesar de tais valores ainda serem preliminares. Os valores de espessura crustal e razão $\mathrm{Vp} / \mathrm{Vs}$, assim como as localizações das estações estão mostrados na Figura 5.

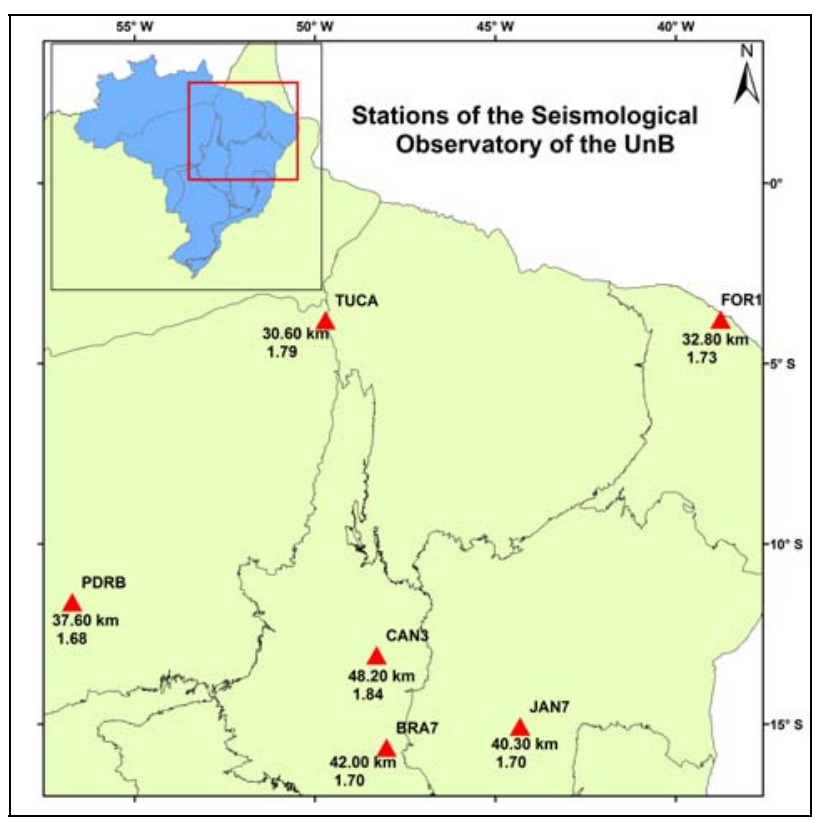

Figura 5 - Localização das estações da Rede Sismográfica Nacional e os valores de espessura crustal e razão $\mathrm{Vp} / \mathrm{Vs}$ para cada uma.

Somente para a estação TUCA se obteve um valor de espessura abaixo do esperado. A razão $\mathrm{Vp} / \mathrm{Vs}$ para esta estação também ficou muito alta $(1,83)$. Isto pode estar diretamente ligado aos seguintes fatores:

- Baixa razão sinal-ruído;

- Presença constante de ruído de origem não identificada;

- Longos períodos sem dados (gaps);

- Poucos telessismos no registro;

- Má calibração do sismômetro ou defeito.

Outro problema encontrado foi o registro de telessismos vindos, em sua maioria, da região andina, ou seja, mesmo azimute. Isso pode criar ambigüidades nos resultados.

Este trabalho teve como foco o método (Função do Receptor no domínio da freqüência). Posteriormente, será feito um trabalho mais detalhado, levando em conta aspectos geológicos e a evolução tectônica para cada região. Isso depende da expansão da Rede Sismográfica
Nacional, com a instalação de estações em pontos ainda não monitorados atualmente.

\section{Agradecimentos}

Os autores agradecem ao apoio do Observatório Sismológico, em especial aos técnicos pelo apoio de campo; DFA e PGNS agradecem ao CNPq e Decanato de Pesquisa e Pós-Graduação (DPP-UnB) pela bolsa de iniciação científica; a Charles Ammon e Jordi Juliá pelos programas disponíveis. GSF agradece a bolsa concedida CNPq processo 302398/2007-4.

\section{Referências}

Langston, C.A., 1979. Structure under Mount Rainier, Washington, inferred from teleseismic body waves. J. Geophys. Res. 85, 4749-4762.

Ammon, C.J., 1991. The isolation effects from teleseismic P-waveforms. Bull. Seism. Soc. Am. 81, 2504-251

Ammom, C. J., G. E. Randall \& G. Zandt, 1990. On the nonuniqueness of receiver functions inversions, $J$. Geophys. Res., 95, 15303-15318.

Asmus, H.E. \& Baisch, P.R. - 1983 - Geological evolution of the Brazilian continental margin. Episodes, 4: 3-9.

Assumpção, M., An, M., Bianchi, M., França, G.S.L., Rocha, M., Barbosa, J.R., Berrocal, J., 2004. Seismic studies of the Brasília Fold Belt as the western border of the São Francisco Craton, Central Brazil. Tectonophysics, 388: 173-185.

França, G.S.L., 2003. Estrutura da crosta no Sudeste e Centro-Oeste do Brasil usando a Função do Receptor. Tese de Doutorado, Instituto de Astronomia, Geofísica e Ciências Atmosféricas-USP (São Paulo, Brasil), 143 p.

Pavão, C. G., 2010. Estudo de descontinuidades crustais na Província Borborema usando a Função do Receptor. Dissertação de mestrado, Programa de Pós Graduação em Geociências Aplicadas, Instituto de Geociências, Universidade de Brasília, 143 p.

Castro , D.L., W. E. Medeiros, E. F. Jardim de Sá, \& J.A.M. Moreira, J.A.M. 1998. Mapa gravimétrico do Nordeste Setentrional do Brasil e margem continental adjacente: interpretação com base na hipótese de isostasia. Rev. Bras. Geof., 16 (2/3):pp 115-131.

DNPM, 1984, Geologia do Brasil, Divisão de geologia e Minerologia, Departamento Nacional de Produção Mineral, 501p.

Jardim de Sá, E.F. - 1994 - A Faixa Seridó (Província Borborema, NE do Brasil) e o seu significado geodinâmico na Cadeia Brasiliana/Pan-Africana. Tese de Doutorado, UnB, Brasília, DF, 804 pp.

Matos, R.M.D. 1992 . The northeast brazilian rift system. Tectonics, 11 (4): pp 766-791. 
Mooney, WD, Laske, G. and Masters, G., 1998. CRUST 5.1: A global crustal model at $5^{\circ} \times 5^{\circ} . \mathrm{J}$. Geophys. Res., 103, 727- 747.

Ussami, N. , N. C. Sá \& E. C. Molina, 1993. Gravity Map of Brazil, 2. Regional and residual isostatic anomalies and their correlation with major tectonic provinces. $J$. Geophys. Res., 98: 2199-2208.

Vilar C. S., 2004, Estrutura tridimensional da onda S na litosfera do Nordeste Brasileiro. ON/MCT:pp 257.

Zandt, G., S. C. Myers \& T. C. Wallace, 1995. Crust and mantle structure across the Basin and Range-Colorado Plateau boundary at $37^{\circ}$ latitude and implications for Cenozoic extensional mechanism, J. Geophys. Res., 100, B6, 10529-10548.

Zhu, L., and H. Kanamori, 2000. Moho depth variation in southernCalifornia from teleseismic receiver functions, $J$. Geophys. Res., 105 , 2969-2980. 